\title{
Fe microenvironments in heat treated rare-earth exchanged montmorillonites
}

\section{Erno Kuzmann ${ }^{1}$ (D) E Eszter M. Kovács ${ }^{2} \cdot$ Zoltan Homonnay $^{1} \cdot$ Szabolcs Csákvári $^{1}$ • Zoltan Klencsár $^{3}$ - Peter Kónya ${ }^{4}$ • Noemi M. Nagy ${ }^{2} \cdot$ Jozsef Kónya $^{2}$}

Published online: 20 August 2019

(C) The Author(s) 2019

\begin{abstract}
The rare-earth bentonites were prepared from Ca-bentonite by suspending Ca-bentonite in rare-earth $(\mathrm{Ce}, \mathrm{La}, \mathrm{Y})$ perchlorate solution. ${ }^{57} \mathrm{Fe}$ Mössbauer spectra of rare earth montmorillonites before heat treatments showed a doublet envelop at room temperature, reflecting dominantly $\mathrm{Fe}^{3+}$ assigned to (cis) octahedral site in the montmorillonite. At the same time, the $80 \mathrm{~K}$ spectra of these rare-earth exchanged montmorillonites revealed an additional magnetically split component, too, associated with iron atoms intercalated in the interlayer space. In the case of heat treated samples $\left(250{ }^{\circ} \mathrm{C}, 360{ }^{\circ} \mathrm{C}\right.$ and $500{ }^{\circ} \mathrm{C}$ for $\left.4 \mathrm{~h}\right)$, a new doublet component associated with $\mathrm{Fe}^{3+}$ at trans octahedral site, appeared in both the $295 \mathrm{~K}$ and $80 \mathrm{~K}$ Mössbauer spectra. Powder X-ray diffractometry (XRD) measurements of the heat treated rare earth montmorillonites revealed that a gradual mineral phase transformation of montmorillonite to muscovite occurred upon the applied heat treatments, being consistent with the completing electron magnetic resonance (EMR) and Mössbauer spectroscopy (MS) results.
\end{abstract}

Keywords Rare earth-montmorillonite $\cdot{ }^{57} \mathrm{Fe}$ Mössbauer spectroscopy $\cdot$ Interlayer Fe $\cdot$ Phase transition · Electron magnetic resonance

This article is part of the Topical Collection on Proceedings of the 5th Mediterranean Conference on the Applications of the Mössbauer Effect (MECAME 2019) and 41st Workshop of the French-speaking Group of Mössbauer Spectroscopy (GFSM 2019), Montpellier, France, 19-23 May 2019

Edited by Pierre-Emmanuel Lippens, Yann Garcia, Moulay-Tahar Sougrati and Mira Ristic $(\dagger)$

Erno Kuzmann

kuzmann@ caesar.elte.hu

Institute of Chemistry, Eötvös Loránd University, Budapest, Hungary

2 Imre Lajos Isotope Laboratory, Department of Physical Chemistry, University of Debrecen, Debrecen, Hungary

3 Centre for Energy Research, HAS, Budapest, Hungary

4 Geological and Geophysical Institute of Hungary, Budapest, Hungary 


\section{Introduction}

Mössbauer spectroscopy has already been successfully applied to show the incorporation of Fe ion into the interlayer space of montmorillonites [1,2]. An unexpected magnetically split component was observed in the ${ }^{57} \mathrm{Fe}$ Mössbauer spectra of certain rare earth (e.g. La, Ce, Gd) cation exchanged montmorillonites at $78 \mathrm{~K}[3,4]$ indicating $\mathrm{Fe}$ ions moving from their octahedral site into the interlayer space.

Our present aim is to study the effect of heat treatment of rare earth montmorillonites on the variation of iron microenvironments by the help of ${ }^{57} \mathrm{Fe} \mathrm{MS}, \mathrm{XRD}, \mathrm{EMR}$ and X-ray fluorescence (XRF) methods.

\section{Experimental}

The original Ca-montmorillonite collected in the region of Istenmezeje, Hungary. Elemental analysis of the original Ca-bentonite resulted in the following composition: $73.29 \% \mathrm{SiO}_{2}$, $18.71 \% \mathrm{Al}_{2} \mathrm{O}_{3}, 1.48 \% \mathrm{Fe}$-oxide, $2.29 \% \mathrm{CaO}$ and $4.23 \% \mathrm{MgO}$. The analysis was performed with RÖNTEC EDR288 energy dispersive X-ray spectrometer.

The rare-earth bentonites were prepared from Ca-bentonite by suspending the Ca-bentonite in rare-earth $(\mathrm{Ce}, \mathrm{La}, \mathrm{Y})$ perchlorate solution under intense stirring for $5 \mathrm{~h}$ at room temperature. $2 \mathrm{~g} \mathrm{Ca}$-bentonite starting material was suspended in $20 \mathrm{~cm}^{3}$ of the rare earth-perchlorate $\mathrm{pH}=$ $5-5.5, \sim 0.1 \mathrm{~mol} \mathrm{dm}^{-3}$ ). The procedure was repeated 3 times. At the end the products were washed with tridistilled water and air-dried. The heat treatment of samples was performed at $250{ }^{\circ} \mathrm{C}, 360{ }^{\circ} \mathrm{C}$ and $500{ }^{\circ} \mathrm{C}$ for $4 \mathrm{~h}$.

Rare earth and iron concentration of samples were determined by an energy dispersive $\mathrm{X}$-ray fluorescence system. The parts of the system were: radioactive source $(185 \mathrm{MBq}$ ${ }^{241} \mathrm{Am}$ for rare earth analysis, tungsten X-ray tube (type: S6000, Oxford Instruments, Scotts Valley, CA 95066, USA) for iron), $\mathrm{Si}(\mathrm{Li})$ detector with $20 \mathrm{~mm}^{2}$ surface, $3.5 \mathrm{~mm}$ evaporated layer, Canberra DSA 1000 digital spectrum analyzer, Canberra Genie 2000 3.0 spectroscopy software.

XRD diffractograms were recorded using a Philips PW1710 powder diffractometer equipped with a $\mathrm{CuK}_{\alpha}$ source and a graphite monochromator (operating at $30 \mathrm{~mA}, 40 \mathrm{kV}$ ). The scan rate was $2^{\circ} 2 \theta / \mathrm{min}$.

${ }^{57} \mathrm{Fe}$ Mössbauer measurements of powdered samples were performed with WISSEL spectrometer in transmission geometry at $80 \mathrm{~K}$ and $298 \mathrm{~K}$ using a JANIS He cryostat and $20 \mathrm{mCi}$ activity ${ }^{57} \mathrm{Co} / \mathrm{Rh}$ sources. The isomer shifts are given relatively to $\alpha$-Fe. The Mössbauer spectra were evaluated by least-square fitting using the MOSSWINN program $[5]$.

$\mathrm{X}$-band electron magnetic resonance (EMR) spectroscopy measurements were performed at room temperature with a Bruker ElexSys E500 spectrometer, in each case on $50 \mathrm{mg}$ powder of Ce-montmorillonite. The conditions of EMR measurements involved a modulation frequency of $100 \mathrm{kHz}$, modulation amplitude of $5 \mathrm{G}$, microwave power of $\sim 2 \mathrm{~mW}$ and microwave frequency of $f \approx 9.3 \mathrm{GHz}$. The spectra were scanned in the magnetic field range of $100 \ldots 10900 \mathrm{G}$ with a sweep time of $\sim 84 \mathrm{~s}$, with 4 sweeps accumulated in each case in 2048 data channels. 


\section{Results and discussion}

Powder X-ray diffractograms of Ce- montmorillonite heat treated at $250{ }^{\circ} \mathrm{C}, 360{ }^{\circ} \mathrm{C}$ and $500{ }^{\circ} \mathrm{C}$ are shown in Fig. 1. The diffractograms correspond well to those reported earlier for rare earth-bentonites (without heat treatment) [4] except the appearance of additional lines of muscovite. The most important difference among the diffractograms was found in the difference of the relative occurrence of muscovite compared to the montmorillonite. The relative occurrence of muscovite gradually increases, the relative occurrence of montmorillonite decreases with increasing temperature of heat treatment. This reflect that a phase transformation of montmorillonite to muscovite occur upon the effect of the heat treatments. The rate of the phase transformation increases with increasing temperature of heat treatment. The decomposition of montmorillonite and smectite to mica phase transformations upon aging has already been reported [6-8].

${ }^{57} \mathrm{Fe}$ Mössbauer spectra, recorded at $293 \mathrm{~K}$ and $80 \mathrm{~K}$, of montmorillonite treated at $250{ }^{\circ} \mathrm{C}$ (a), $360{ }^{\circ} \mathrm{C}$ (b) and $500{ }^{\circ} \mathrm{C}$ are shown in Fig. 2. The room temperature Mössbauer spectra of heat treated rare-earth substituted samples were decomposed into two doublets. The major doublet (D1), with average Mössbauer parameters indicated in Table 1, was assigned to $\mathrm{Fe}^{3+}$ at the (cis) octahedral sites, since Mössbauer spectra of rare earth montmorillonites before heat treatments showed a doublet with similar parameters at room temperature, reflecting dominantly $\mathrm{Fe}^{3+}$ at (cis) octahedral site [4]. The minor doublet D2, appeared in the spectra of heat treated samples, have Mössbauer parameters (Table 1) with values the quadrupole splitting being about the twice than those belonging to doublet D1, which suggest the assignment of doublet $\mathrm{D} 2$ to $\mathrm{Fe}^{3+}$ at trans octahedral site.

At the same time, the $80 \mathrm{~K}$ spectra of $\mathrm{Ce}$, La and $\mathrm{Y}$ montmorillonites revealed an additional magnetically split component, S, too, associated with iron atoms intercalated in the interlayer space. This result corresponds to those obtained earlier [3, 4]. Similar magnetic component was found in the $80 \mathrm{~K}$ spectra of montmorillonite samples before the heat treatment $[3,4]$. In the case of heat treated samples, the new doublet component D2 $\left(\Delta \approx 2 \Delta_{\text {cis }}\right)$, corresponding to $\mathrm{Fe}^{3+}$ at trans octahedral site, appeared in both the $295 \mathrm{~K}$ and $80 \mathrm{~K}$ Mössbauer spectra (Fig. 2).

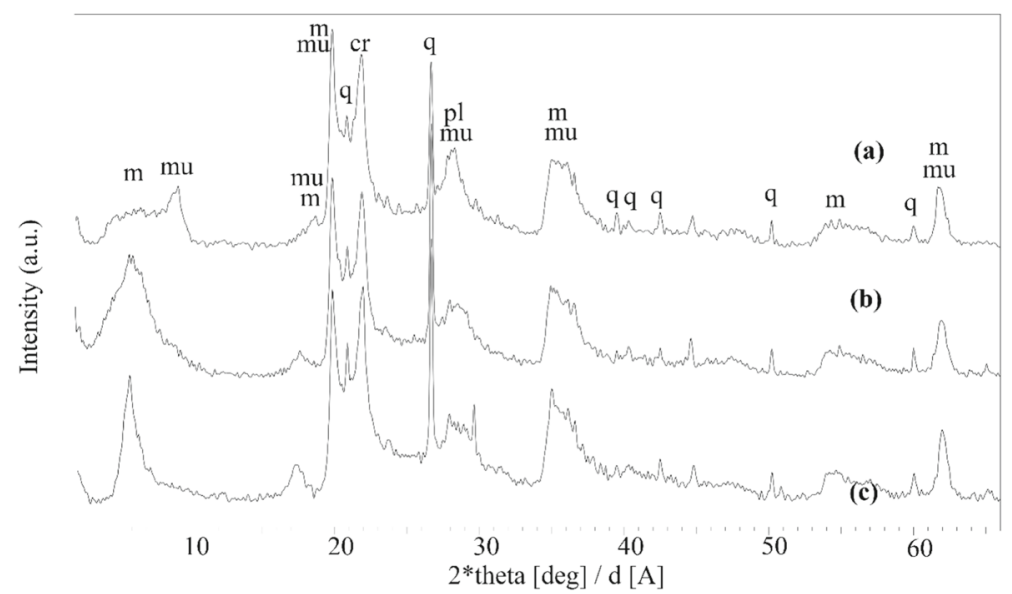

Fig. 1 XRD patterns of Ce-montmorillonite heat treated at $250{ }^{\circ} \mathrm{C}$ (a), $360{ }^{\circ} \mathrm{C}$ (b) and $500{ }^{\circ} \mathrm{C}(\mathrm{c}),(\mathrm{m}$ : monmorillonite, m:montmorillonite, mu:muscovite, q:quartz, cr:crystoballite and pl:plagioclase 

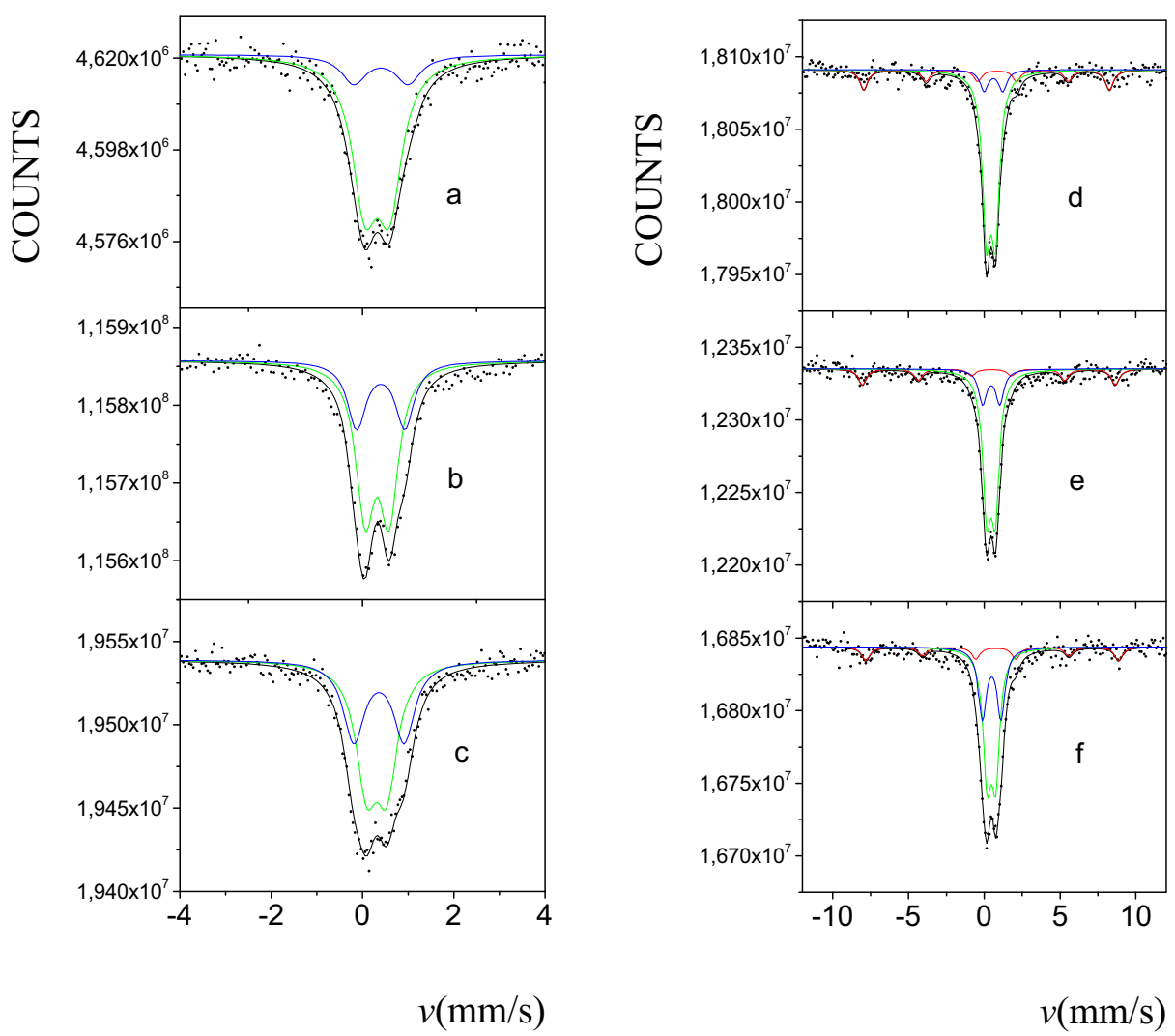

Fig. $2{ }^{57} \mathrm{Fe}$ Mössbauer spectra, recorded $293 \mathrm{~K}$ (on the left) and at $80 \mathrm{~K}$ (on the right), of Ce-bentonites heat treated at $250{ }^{\circ} \mathrm{C}(\mathrm{a}, \mathrm{d}), 360{ }^{\circ} \mathrm{C}(\mathrm{b}, \mathrm{e})$ and $500{ }^{\circ} \mathrm{C}(\mathrm{c}, \mathrm{f})$

We have found that the relative occurrence of this new doublet D2 increased gradually with the increase of the temperature of the heat treatment, while the relative fraction of magnetically split component S slightly decreased.

Table 1 Mössbauer parameters of heat treated Ce-bentonites

\begin{tabular}{|c|c|c|c|c|c|c|c|}
\hline \multicolumn{2}{|c|}{ Temperature of heat treatment } & \multicolumn{2}{|l|}{$250{ }^{\circ} \mathrm{C}$} & \multicolumn{2}{|l|}{$360{ }^{\circ} \mathrm{C}$} & \multicolumn{2}{|l|}{$500{ }^{\circ} \mathrm{C}$} \\
\hline \multicolumn{2}{|c|}{ Measuring temperature } & $293 \mathrm{~K}$ & $80 \mathrm{~K}$ & $293 \mathrm{~K}$ & $80 \mathrm{~K}$ & $293 \mathrm{~K}$ & $80 \mathrm{~K}$ \\
\hline \multirow[t]{3}{*}{ D1 } & $A(\%)$ & 82.8 & 69.9 & 68.7 & 65.4 & 59.2 & 53.4 \\
\hline & $\delta(\mathrm{mm} / \mathrm{s})$ & 0.32 & 0.44 & 0.32 & 0.44 & 0.31 & 0.46 \\
\hline & $\Delta(\mathrm{mm} / \mathrm{s})$ & 0.54 & 0.58 & 0.52 & 0.55 & 0.44 & 0.55 \\
\hline \multirow[t]{3}{*}{ D2 } & $A(\%)$ & 17.2 & 9.9 & 31.3 & 17.2 & 40.8 & 31.0 \\
\hline & $\delta(\mathrm{mm} / \mathrm{s})$ & 0.40 & 0.50 & 0.40 & 0.45 & 0.36 & 0.49 \\
\hline & $\Delta(\mathrm{mm} / \mathrm{s})$ & 1.19 & 1.23 & 1.08 & 1.13 & 1.10 & 1.22 \\
\hline \multirow[t]{3}{*}{$\mathrm{S}$} & $A(\%)$ & & 20.2 & & 17.3 & & 15.6 \\
\hline & $\delta(\mathrm{mm} / \mathrm{s})$ & & 0.50 & & 0.41 & & 0.51 \\
\hline & $B(\mathrm{~T})$ & & 50.4 & & 51.8 & & 51.8 \\
\hline
\end{tabular}


Taking into consideration the XRD results for the partial montmorillonite to muscovite transformation (Table 1) and the knowledge that iron occupies $\mathrm{Fe}^{3+}$ trans octahedral site in muscovite, which does not often occur with montmorillonite, D2 doublet can be mainly associated with iron atoms being $\mathrm{Fe}^{3+}$ at trans octahedral site in muscovite. The Mössbauer parameters obtained for D2 are also consistent with those characteristic $\mathrm{Fe}^{3+}$ at trans octahedral site [8]. In this way, the Mössbauer spectroscopy can follow the montmorillonite to muscovite phase transformation upon the heat treatment in the rare-earth montmorillonites. However, the relative areas of components presented in Table 1 cannot give exact data on the rate of the transformation because the D1 doublet can be considered as the superposition of $\mathrm{Fe}^{3+}$ atoms being at cis octahedral site both in montmorillonite and in muscovite. However, this may not be significant since $\mathrm{Fe}^{3+}$ in muscovite prefers the cis octahedral site [9]. Another problem of the analysis can be that the room temperature Mössbauer spectra should contain one more doublet in strong overlapping mainly with the D1 doublet, belonging to the superparamagnetic state of interlayer iron atoms which presence is indicated by the sextets in the $80 \mathrm{~K}$ spectra [4]. In spite of these difficulties the gradually increasing transformation of montmorillonite to muscovite with the temperature of heat treatment can be followed by Mössbauer spectroscopy which corroborate the XRD results. If we take into consideration the relative area contribution of interlayer iron in $293 \mathrm{~K}$ spectra correspondingly that of the sextets in the $80 \mathrm{~K}$ spectra, furthermore supposing all $\mathrm{Fe}^{3+}$ in muscovite being at trans octahedral site, we can obtain data from the Mössbauer analysis for the rate of transformation which are consistent with those derived from the XRD analysis considering the iron content of the samples.

The slight decrease, with the temperature of heat treatment, of the occurrence of the additional magnetically split component, $\mathrm{S}$, in the $80 \mathrm{~K}$ spectra, reflecting interlayer iron in these heat treated rare earth montmorillonites, is consistent with the partial transformation of montmorillonite upon the heat treatments.

$\mathrm{X}$-band EMR spectra of the heat treated rare earth montmorillonite samples are shown in Fig. 3. The signal extending from ca. $700 \mathrm{G}$ to $2000 \mathrm{G}$, which range — denoted with " $\mathrm{Fe}^{3+}$

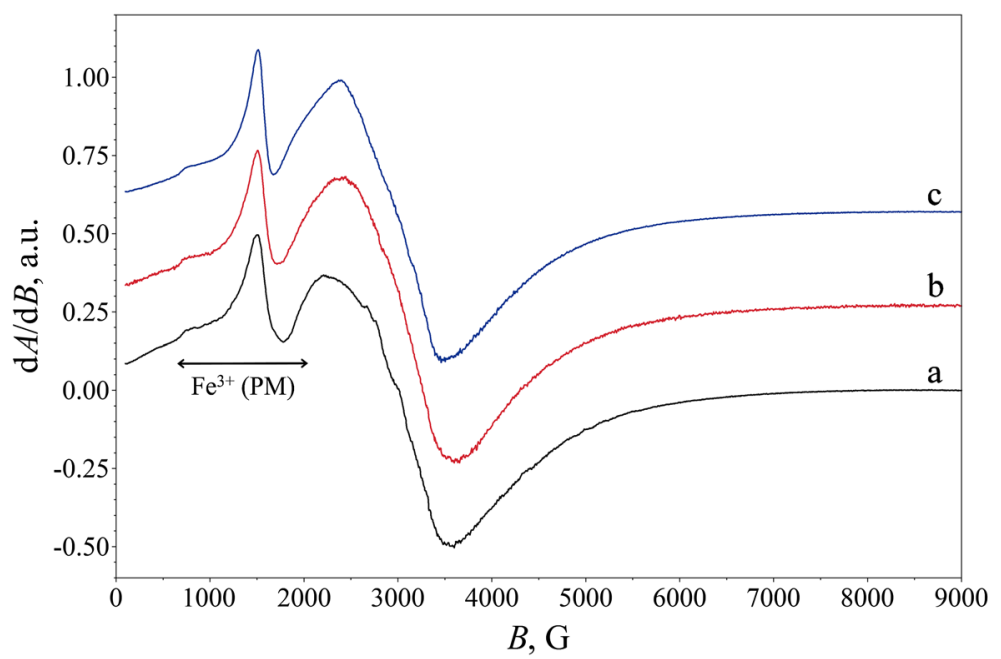

Fig. 3 EMR spectra of Ce-bentonites heat treated at $250{ }^{\circ} \mathrm{C}$ (a), $360^{\circ} \mathrm{C}$ (b) and $500^{\circ} \mathrm{C}$ (c). Apart from an arbitrary shift along the vertical axis, the spectra are proportional to $\mathrm{d} A / \mathrm{d} B$, i.e. the first derivative of the power of microwave absorption with respect to the applied magnetic field. The signal observed in the magnetic field range denoted with " $\mathrm{Fe}^{3+}(\mathrm{PM})$ " refers to the presence of paramagnetic $\mathrm{Fe}^{3+}$ ions in a variety of rhombic crystal field environments 
(PM)" on Fig. 3 - is equivalent to $g_{\text {eff }} \approx 9.5 \ldots 3.3$, refers to the presence of paramagnetic $\mathrm{Fe}^{3+}$ ions being situated in a variety of rhombic crystal field environments. In accordance with previous results [10], this signal may be associated with $\mathrm{Fe}^{3+}$ ions at octahedral sites with various degree of rhombic distortion. The shape of the EMR signal in this range refers to the presence of a distribution in the rhombicity, and consequently to a corresponding distribution in the EFG asymmetry parameter $(\eta)$ associated with octahedral $\mathrm{Fe}^{3+}$ ligand field environments [11]. This is expected to lead to a moderate quadrupole splitting distribution in corresponding ${ }^{57} \mathrm{Fe}$ Mössbauer spectra, possibly appearing as an additional broadening of the absorption peaks of the associated quadrupole doublet(s). The montmorillonite to muscovite phase transformation revealed by the XRD diffractograms (Fig. 1), and the related change in the ratio of cis and trans octahedral $\mathrm{Fe}^{3+}$ site occurrences may be connected to the gradual change (narrowing) in the shape of the EMR signal at around $1580 \mathrm{G}\left(g_{\text {eff }} \approx 4.2\right)$ as the heat treatment temperature increases from $250{ }^{\circ} \mathrm{C}$ (Fig. 3a) to $500{ }^{\circ} \mathrm{C}$ (Fig. 3c).

Beside the above treated paramagnetic component, the EMR spectra of Ce-bentonites also display a broad (with a peak-to-peak width of ca. $\Gamma_{\mathrm{pp}} \approx 10^{3} \mathrm{G}$ ) component centered at around $3000 \mathrm{G}\left(g_{\text {eff }} \approx 2.2\right)$, which is a typical trait of montmorillonites with a high iron concentration [10], and can originate from a multitude of small particles with exchange coupled magnetic ions, such as iron oxides and/or iron oxide hydrates intercalated in the interlayer space [10]. The same particles may then be responsible for the appearance of the sextet component in the ${ }^{57} \mathrm{Fe}$ Mössbauer spectra at $80 \mathrm{~K}$ (Table 1, Fig. 2).

Overall the EMR spectra appear to be consistent with the XRD and Mössbauer spectroscopy results.

\section{Conclusions}

XRD indicated a partial phase transformation of montmorillonite to muscovite in rare-earth substituted montmorillonites after heat treatments at $250{ }^{\circ} \mathrm{C}, 360{ }^{\circ} \mathrm{C}$ and $500{ }^{\circ} \mathrm{C}$, which rate showed a gradual increase with increasing temperature of the heat treatment. Simultaneously, a new doublet, assigned to $\mathrm{Fe}^{3+}$ trans octahedral site, appeared in the ${ }^{57} \mathrm{Fe}$ Mössbauer spectra of the heat treated rare-earth substituted montmorillonites. By attributing the occurrence of $\mathrm{Fe}^{3+}$ trans octahedral sites being in muscovite, the changes observed in the Mössbauer spectra with the heat treatments were interpreted in the term of montmorillonite to muscovite phase transformation and completed the XRD results. Furthermore, an additional magnetically split component in the $80 \mathrm{~K}$ spectra showed the presence of interlayer iron in these of heat treated rare-earth montmorillonites. The EMR spectra were consistent with the presence of iron oxides and/or iron oxide hydrates intercalated in the interlayer space, thereby corroborating the Mössbauer spectroscopy results.

Acknowledgements Open access funding provided by Eötvös Loránd University (ELTE). The financial supports from NKFIH OTKA (No. K115913, K115784, K131963, and K120265) and Hungarian-Croatian S\&T (No TÉT_16-1-2016-0002) as well as by the EU and co-financed by the European Regional Development Fund under the project GINOP-2.3.2-15-2016-00008 grants are acknowledged. Z.K. expresses thanks to Prof. Ferenc Simon (Institute of Physics, Budapest University of Technology and Economics, Budapest, Hungary) for making available the applied spectrometer for recording the EMR spectra.

Open Access This article is distributed under the terms of the Creative Commons Attribution 4.0 International License (http://creativecommons.org/licenses/by/4.0/), which permits unrestricted use, distribution, and 
reproduction in any medium, provided you give appropriate credit to the original author(s) and the source, provide a link to the Creative Commons license, and indicate if changes were made.

\section{References}

1. Komlósi, A., Kuzmann, E., Nagy, N.M., Homonnay, Z., Kubuki, S., Kónya, J.: Incorporation of Fe in the interlayer of Na-bentonite via treatment with $\mathrm{FeCl} 3$ in acetone. Clay Clay Miner. 55, 91-97 (2007)

2. Kuzmann, E., Garg, V.K., Singh, H., de Oliveira, A.C., Pati, S.S., Homonnay, Z., Rudolf, M., Molnár, Á.M., Kovács, E.M., Baranyai, E., Kubuki, S., Nagy, N.M., Kónya, J.: Mössbauer study of pH dependence of iron-intercalation in montmorillonite. Hyperfine Interact. 237(1), 16 (2016)

3. Kuzmann, E., Singh, L.H., Garg, V.K., de Oliveira, A.C., Kovács, E.M., Molnár, Á.M., Homonnay, Z., Kónya, P., Nagy, M.N., Kónya, J.: Mössbauer study of the effect of rare earth substitution into montmorillonite. Hyperfine Interact. 237(1), 1-8 (2016)

4. Kovács, E.M., Erdélyiné Baradács, E., Kónya, P., Kovács-Pálffy, P., Harangi, S., Kuzmann, E., Kónya, J., Nagy, N.M.: Preparation and structure's analyses of lanthanide (Ln) -exchanged bentonites. Colloids and Surfaces A: Physicochem. Eng. Aspects. 522, 287-294 (2017)

5. Klencsár, Z., Kuzmann, E., Vértes, A.: User-friendly software for Mössbauer spectrum analysis. J. Radioanal. Nucl. Chem. Artic. 210(1), 105-118 (1996)

6. Bala, P., Samantary, B.K., Srivastava, S.K.: Dehydration transformation in Ca-montmorillonite. Bull. Mater. Sci. 23, 61-67 (2000)

7. Keller, W.D., Reynolds, R.C., Inoue, A.: Morphology of clay minerals in the smectite-to-illite conversion series by scanning electron microscopy. Clay Clay Miner. 34, 187-197 (1986)

8. Stevens, J.G., Pollak, H., Li, Z., Stevens, V.G., White, R.M., Gibson, J.L.: Mössbauer Handbook, Mineral References and Mineral Data. Mössbauer Effect Data Center, Asheville (1983)

9. Dainyak, L.G., Drits a, V.: A model for the interpretation of Mössbauer spectra of muscovite. Eur. J. Mineral. 21, 99-106 (2009)

10. Lück, R., Stösser, R., Gyepesová, C., Slosiariková, H., Kolditz, L.: Study of Montmorillonites from Several Deposits. Chem. Papers 47, 79-84 (1993)

11. Klencsár, Z., Köntös, Z.: EPR analysis of Fe3+and Mn2+ complexation sites in fulvic acid extracted from lignite. J. Phys. Chem. A. 122, 3190-3203 (2018)

Publisher's note Springer Nature remains neutral with regard to jurisdictional claims in published maps and institutional affiliations. 